\title{
Improved sensitization effect of sunitinib in cancer cells of the esophagus under hypoxic microenviroment
}

\author{
YU-QIONG DING ${ }^{1 *}$, QIN QIN $^{2 *}$, YAN YANG $^{2 *}$, XIN-CHEN SUN ${ }^{2}$, XI YANG $^{2}$, HONG-CHENG ZHU $^{2}$, \\ XIAO-CHEN CHEN $^{2}$, HAO ZHANG ${ }^{2}$, YUE-HUA YANG ${ }^{2}$, LEI GAO ${ }^{1}$, JU-DONG LUO ${ }^{1}$ and XI-FA ZHOU ${ }^{1}$ \\ ${ }^{1}$ Department of Radiotherapy, Changzhou Cancer Hospital of Soochow University, Changzhou, Jiangsu 213001; \\ ${ }^{2}$ Department of Radiotherapy, The First Affiliated Hospital of Nanjing Medical University, Nanjing, Jiangsu 210029, P.R. China
}

Received May 25, 2015; Accepted September 9, 2016

DOI: $10.3892 / 01.2016 .5247$

\begin{abstract}
Radiotherapy is widely used in esophageal squamous cell carcinoma (ESCC) treatment. Promoting the radiation sensitivity of cancer cells is required. Recent studies have shown that sunitinib can inhibit the growth of several cancer lines. However, few studies on the radiosensitive effect of sunitinib on ESCC cells under hypoxic conditions have been conducted. In the present study, the radiosensitive effects of sunitinib on human ESCC cells were assessed, and the underlying mechanisms were explored. ESCC cells were exposed to hypoxia and treated with sunitinib at different concentrations prior to irradiation. Sunitinib potently inhibited ESCC cell proliferation in an MTT assay. In a clonogenic survival assay, sunitinib sensitized hypoxic ESCC cells to radiation, with sensitizing enhancement ratios of 1.31-1.59. In addition, sunitinib promoted the apoptosis of ESCC cells, but did not alter their cell cycle distribution. Radiosensitization was accompanied by inhibition of the radiation-induced upregulation of hypoxia-inducible factor (HIF)-1 $\alpha$ and vascular endothelial growth factor (VEGF) expression. Thus, sunitinib confers radiosensitivity to esophageal cancer cells, which is associated with the downregulation of HIF-1 $\alpha$ and VEGF expression. Sunitinib can be a promising radiosensitizer for esophageal cancer radiotherapy.
\end{abstract}

\section{Introduction}

Esophageal cancer is the eighth most common cancer and the sixth leading cause of cancer mortality, which causes >30 million mortalities worldwide and 15 million mortalities

Correspondence to: Dr Xi-Fa Zhou, Department of Radiotherapy, Changzhou Cancer Hospital of Soochow University, 1 Huaide North Road, Zhonglou, Changzhou, Jiangsu 213001, P.R. China

E-mail: zhouxifa1949@163.com

*Contributed equally

Key words: radiosensitization, HIF-1 $\alpha$, sunitinib, esophageal cancer, hypoxia in China, almost half of the total mortality, each year (1-3). Esophageal squamous cell carcinoma (ESCC) is the dominant histopathological subtype of esophageal cancer (1-3). Radiotherapy has been used either as a definitive therapy for esophageal cancer patients with locally advanced disease or as an adjuvant therapy following radical esophagectomy for esophageal cancer patients (1-3). However, an hypoxic microenvironment exists in esophageal carcinomas, which leads to radiation resistance and poor clinical outcomes, and may be an important determinant of radioresistance $(4,5)$. Free oxygen radicals are generated during radiotherapy that induce DNA damage and kill tumor cells. The lack of oxygen directly activates the expression of hypoxia-inducible factor 1 (HIF-1), which consists of an oxygen-sensitive subunit, HIF-1 $\alpha$, and a constitutively expressed subunit, $\operatorname{HIF}-1 \beta(5,6)$. HIF-1 is a pivotal regulatory factor that enables tumor cells to endure an hypoxic microenvironment, and promotes tumor growth, angiogenesis, invasion and metastasis (6). Additionally, HIF-1 activates the transcription of downstream genes such as vascular endothelial growth factor (VEGF), and indirectly reflects the extent of carcinoma oxygenation $(6,7)$. Overexpression of HIF-1 $\alpha$ has been reported to be associated with a poor prognosis following radiotherapy in patients with esophageal cancer (8). The suppression of HIF-1 $\alpha$ expression may reversed by the radioresistant phenotype of hypoxic cancer cells $(9,10)$.

Sunitinib, a highly selective multi-targeted receptor tyrosine kinase inhibitor, has been reported to have direct antitumor effects against various cancers, and to enhance tumor radiosensitivity in breast tumors (11), pancreatic cancer (12) and colon cancer (13). In particular, sunitinib suppressed cycling hypoxia in tumors and maximized the effects of combination therapy with anti-angiogenic drugs (14). Furthermore, sunitinib was shown to downregulate the expression of HIF-1 $\alpha$, and subsequently, that of VEGF, in human embryonic stem cells (15) and HT-29 colon cancer cells (16).

However, whether sunitinib suppresses HIF-1 $\alpha$ in esophageal cancer cells has not been elucidated yet. In the present study, it was demonstrated that sunitinib could inhibit HIF-1 $\alpha$ and VEGF expression in ESCC cells, and thus mediate the radiosensitization of ESCC cells to irradiation (IR) significantly. 


\section{Materials and methods}

Reagents and cell lines. Sunitinib (S1042; Selleck Chemicals, Houston, TX, USA) was dissolved in dimethyl sulfoxide (DMSO; Sigma-Aldrich; Merck Millipore, Darmstadt, Germany) as a concentrated stock solution of $10 \mathrm{mg} / \mathrm{ml}$. The human malignant esophageal cancer cell line ECA109 was obtained from the Shanghai Institute of Cell Biology (Shanghai, China). Cells were cultured in Dulbecco's modified Eagle's medium (Gibco; Thermo Fisher Scientific, Inc., Waltham, MA, USA) supplemented with $10 \%$ fetal bovine serum (Hyclone; GE Healthcare Life Sciences, Logan, UT, USA) and $1 \%$ penicillin/streptomycin (Invitrogen; Thermo Fisher Scientific, Inc.). Cells were kept under conditions of 5\% $\mathrm{CO}_{2}$ in an incubator at $37^{\circ} \mathrm{C}$.

Hypoxia and IR protocols. Hypoxia was induced by incubating cells in an hypoxia chamber [a glass chamber maintaining $0.5-1.0 \%$ partial pressure of oxygen $\left.\left(\mathrm{pO}_{2}\right)\right]$. IR was performed at $566 \mathrm{cGy} / \mathrm{min}$ using an X-ray medical linear accelerator (Elekta AB, Stockholm, Sweden). Cells were irradiated at a single dose at room temperature.

MTT assay. Cell cytotoxicity effect was measured by MTT assay. ECA109 cells were seeded into 96-well plates at a concentration of $5-6 \times 10^{3}$ cells/well and allowed to adhere. Next, the cells were treated with increasing sunitinib doses $(0$, $1,2.5,5,10,15,20$ and $25 \mu \mathrm{M})$. After 24 or $48 \mathrm{~h}$ of exposure to sunitinib, $10 \mu \mathrm{l}$ of $5 \mathrm{mg} / \mathrm{ml}$ MTT reagent was added to each well. After incubation for $4 \mathrm{~h}$, the supernatants were removed, and $150 \mu 1$ of DMSO was added to dissolve the MTT crystals (formazan). The absorbance of the plates was measured at a wavelength of $490 \mathrm{~nm}$ using a microplate reader (ELx800; BioTek Instruments, Inc., Winooski, VT, USA). The half maximal inhibitory concentration $\left(\mathrm{IC}_{50}\right)$ values were calculated using the SPSS 17.0 software (SPSS, Inc., Chicago, IL, USA). Each experiment was performed thrice.

Cell proliferation assay. ECA109 cells were seeded into 96-well plates. The cells were incubated overnight and then treated with the indicated concentrations of sunitinib (1 or $2.5 \mu \mathrm{M}$ ) under normoxic or hypoxic conditions for $24 \mathrm{~h}$, and then subjected to X-rays at $8 \mathrm{~Gy}$. After $24 \mathrm{~h}$, cell proliferation was assessed by MTT assay. The percentage cell growth inhibition for each group was calculated by adjusting the control group to $100 \%$. Each experiment was performed thrice.

Clonogenic assay. ECA109 cells were seeded into 6-well plates. The cells were incubated overnight and then treated with the indicated concentrations of sunitinib (1 or $2.5 \mu \mathrm{M})$ or DMSO (control) under normoxic or hypoxic conditions for $24 \mathrm{~h}$, and then subjected to X-rays at 2, 4, 6 or $8 \mathrm{~Gy}$. Subsequently, the cells were incubated at $37^{\circ} \mathrm{C}$ for $10-14$ days under normoxic conditions, fixed with methanol and stained with Giemsa for $30 \mathrm{~min}$. Finally, the plates were examined under the microscope, and the number of colonies with $\geq 50$ cells was counted. The cell survival curves were fitted according to a single-hit multi-target model, and the survival enhancement ratio (SER) was calculated as the ratio of the mean inactivation dose in control cells divided by the mean inactivation dose in sunitinib-treated cells. Each experiment was performed thrice.

Apoptosisassay. Annexin-V/fluorescein isothiocyanate (FITC) and propidium iodide (PI) dual staining was performed to determine the percentage of apoptotic cells. The cells were seeded into 6-well plates and treated with or without sunitinib (1 or $2.5 \mu \mathrm{M}$ ) under normoxic or hypoxic conditions for $24 \mathrm{~h}$. Subsequently, the cells were subjected to X-ray IR ( $8 \mathrm{~Gy}$ ). The cells were collected $48 \mathrm{~h}$ after IR and analyzed with BD Pharmingen $^{\mathrm{TM}}$ FITC Annexin V Apoptosis Detection kit (BD Biosciences, Franklin Lakes, NJ, USA) by flow cytometry. Each experiment was performed thrice.

Cell cycle analysis. ECA109 cells were incubated in 6-well plates $\left(1 \times 10^{6}\right.$ cells/well) and then divided into the following groups: Normoxia (Norm), hypoxia (Hypo), sunitinib $1 \mu \mathrm{M}$ (SU $1 \mu \mathrm{M})$ and sunitinib $2.5 \mu \mathrm{M}(\mathrm{SU} 2.5 \mu \mathrm{M})$. The groups of SU $1 \mu \mathrm{M}$ and SU $2.5 \mu \mathrm{M}$ were pretreated with $1 \mu \mathrm{M}$ or $2.5 \mu \mathrm{M}$ sunitinib. After $24 \mathrm{~h}$, all cells were collected and washed with cold $1 \mathrm{X}$ PBS, and then resuspended in $70 \%$ ethanol at $4^{\circ} \mathrm{C}$ overnight. The cells were incubated with $6 \mu \mathrm{l}$ of $1 \mathrm{~g} / \mathrm{l}$ RNase A, $1 \mathrm{ml}$ of $1 \mathrm{mg} / \mathrm{ml} \mathrm{PI}$ and $400 \mu \mathrm{l}$ of PBS at room temperature for $15 \mathrm{~min}$. The cell cycle distribution was analyzed using flow cytometry. Each experiment was performed thrice.

Western blot analysis. Total proteins were extracted from the cells using SDS Lysis Buffer (Sigma-Aldrich; Merck Millipore) at $24 \mathrm{~h}$ after the last sunitinib treatment under normoxic or hypoxic conditions. The protein concentrations of the supernatants were determined by bicinchoninic acid assay. Equal amounts of protein were loaded into each lane, and proteins were separated by $10 \%$ SDS-PAGE and transferred to polyvinylidene difluoride membranes (EMD Millipore, Billerica, MA, USA). The membranes were blocked with 5\% skim milk, incubated with primary antibodies against HIF-1 $\alpha$ (14179; dilution, 1:250; Cell Signaling Technology, Inc., Danvers, MA, USA), VEGF (sc-507; dilution, 1:250) and GAPDH (sc-25778; dilution, 1:1,000) (Santa Cruz Biotechnology, Inc., Dallas, TX, USA) at $4^{\circ} \mathrm{C}$ overnight, and then incubated with horseradish peroxidase-conjugated secondary antibodies (BS13278; dilution, 1:1,000; Bioworld Technology, Inc., St. Louis Park, MN, USA) for $1 \mathrm{~h}$ at room temperature. The immunoblotted proteins were visualized with enhanced chemiluminescence reagents (EMD Millipore), and the signals were detected using the ChemiDoc ${ }^{\mathrm{TM}}$ XRS+ imaging system (Bio-Rad Laboratories, Inc., Hercules, CA, USA) and analyzed with Quantity One quantitation software (Bio-Rad Laboratories, Inc.).

Statistical analysis. All data are expressed as means \pm standard deviation. Data were analyzed using SPSS 17.0 software (SPSS, Inc.). Survival curves were fitted using GraphPad Prism 5.0 (GraphPad Software, Inc., La Jolla, CA, USA). Student's $t$ test was applied to compare the groups. $\mathrm{P}<0.05$ was considered to indicate a statistically significant difference.

\section{Results}

Sunitinib inhibits human ESCC cell proliferation. MTT assay was performed at 24 and $48 \mathrm{~h}$ following sunitinib 
A

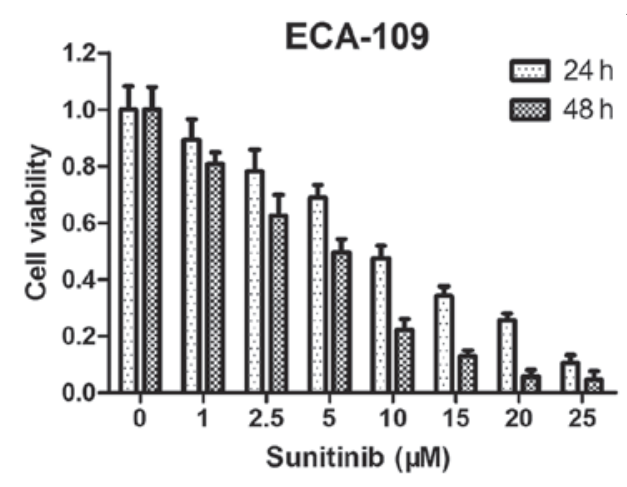

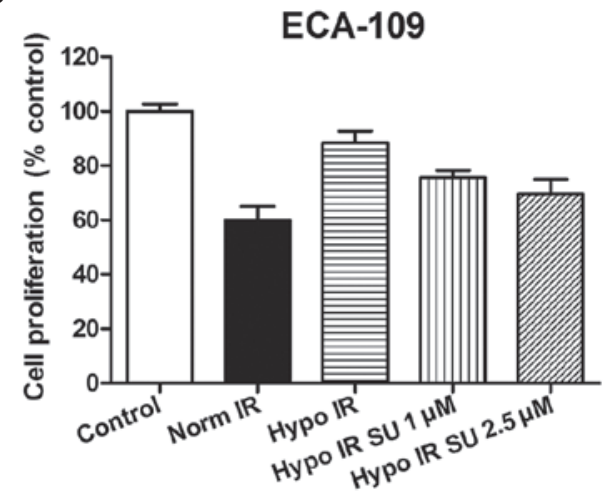

Figure 1. Effect of sunitinib on cell proliferation. (A) MTT assay was performed to assess the cytotoxicity effect of treatment with increasing doses of sunitinib $(0,1,2.5,5,10,15,20$ and $25 \mu \mathrm{M})$ for 24 or $48 \mathrm{~h}$ in ECA109 cells. (B) ECA109 cells were treated with sunitinib $(1$ or $2.5 \mu \mathrm{M})$ under normoxic or hypoxic conditions for $24 \mathrm{~h}$. Cell proliferation was measured by MTT assay. The percentage of cell growth inhibition was calculated by adjusting the control group to $100 \%$. Data were presented as the men \pm standard error of the mean and were normalized to the control cells. Hypo, hypoxia; Norm, normoxia; SU, sunitinib; IR, irradiation.

A

ECA-109

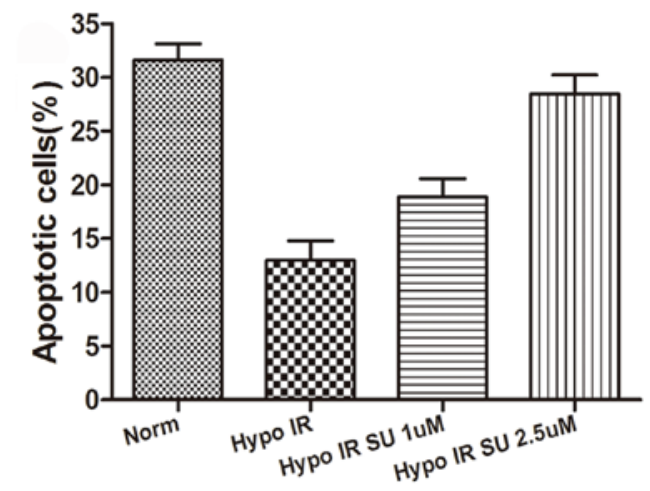

C
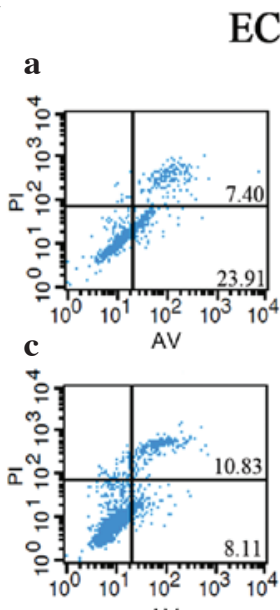

ECA-109

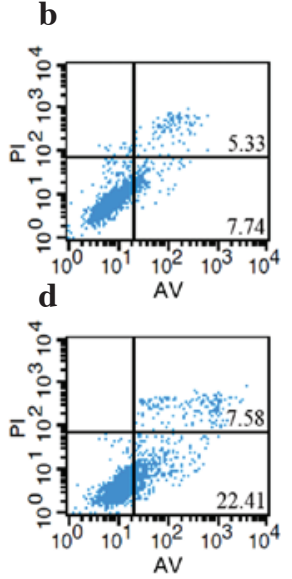

B

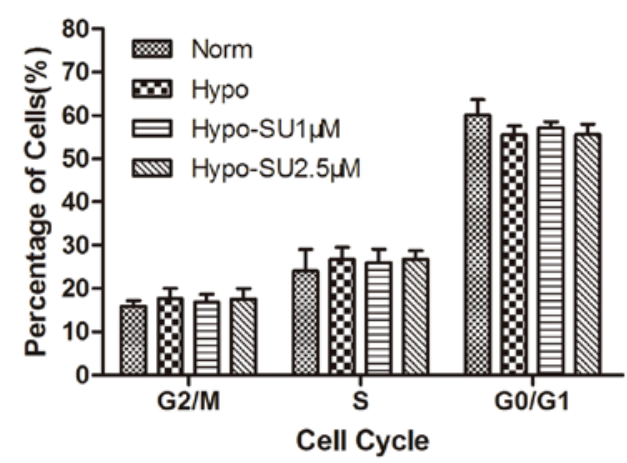

D

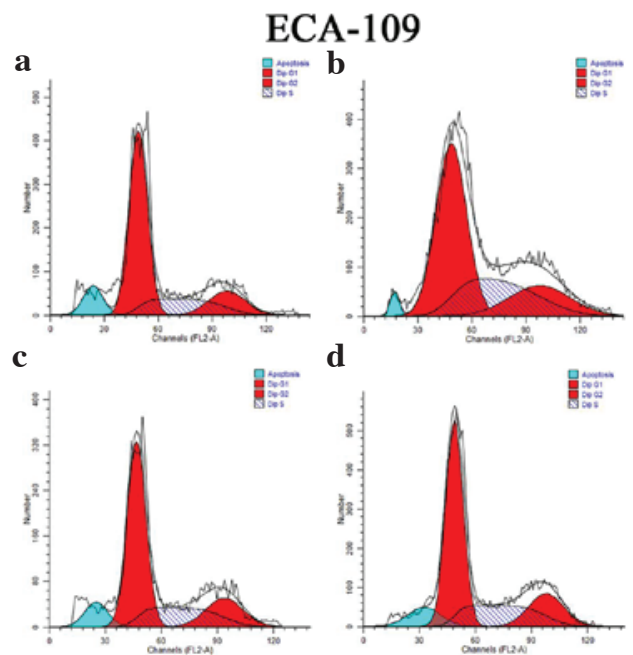

Figure 2. Effect of sunitinib on cell apoptosis and cell cycle distribution. (A and C) ECA109 cells were treated with sunitinib (1 or $2.5 \mu$ M) under normoxic or hypoxic conditions for $24 \mathrm{~h}$ and then subjected to X-ray IR (8 Gy). Following $48 \mathrm{~h}$, the percentage of apoptotic cells was evaluated using flow cytometry. (B and D) ECA109 cells were divided into four groups: (a) Norm, (b) Hypo, (c) SU $1 \mu \mathrm{M}$ and (d) SU $2.5 \mu \mathrm{M} \mu \mathrm{M}$. Cells were subjected to X-ray IR (6 Gy) and analyzed using flow cytometry $24 \mathrm{~h}$ later. Data were presented as the mean \pm standard error of the mean. Hypo, hypoxia; Norm, normoxia; SU, sunitinib; IR, irradiation; PI, propidium iodide; AV, Annexin V/FITA; Dip, Diploid; FL2-A, FL2-area.

administration at various concentrations $(\leq 25 \mu \mathrm{M})$ to determine the sensitivity of human ESCC cells to sunitinib as a single agent. The $\mathrm{IC}_{50}$ value for ECA109 cells at $24 \mathrm{~h}$ was $7.07 \mu \mathrm{M}$.
Fig. 1A demonstrates that sunitinib produced a cytotoxic effect in a dose-dependent manner. The survival rates in 1 or $2.5 \mu \mathrm{M}$ sunitinib-treated ECA109 cells for $24 \mathrm{~h}$ were 89.23 and $78.29 \%$, 
A

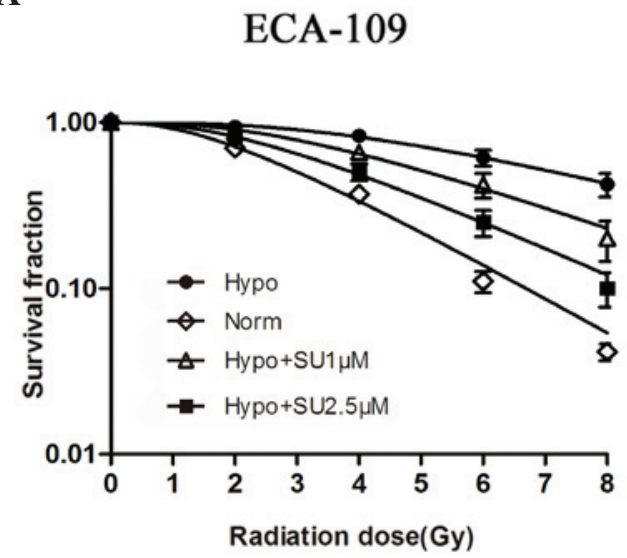

B

$\begin{array}{ccccc}\text { Hypoxia(24h) } & - & + & + & + \\ \text { Sunitinib }(\mu \mathrm{M}) & - & - & 1.0 & 2.5\end{array}$

Figure 3. Effect of sunitinib on colony formation and expression of HIF-1 $\alpha$ and VEGF in esophageal squamous cell carcinoma cells. (A) Colony formation assay of ECA109 cells was performed to assess the sunitinib radiosensitization activity. Cells were treated with sunitinib (1 or $2.5 \mu \mathrm{M})$ under normoxic or hypoxic conditions for $24 \mathrm{~h}$ and then subjected to X-rays at 2, 4, 6 or $8 \mathrm{~Gy}$. (B) The protein levels of HIF-1 $\alpha$ and VEGF in ECA109 cells were evaluated using western blot analysis. Hypo, hypoxia; Norm, normoxia; SU, sunitinib; VEGF, vascular endothelial growth factor; HIF-1 $\alpha$, hypoxia-inducible factor-1 $\alpha$.

Table I. Radiosensitization activity of sunitinib in hypoxic ECA109 cells.

\begin{tabular}{lcccc}
\hline ECA109 cells & $\mathrm{D}_{0}{ }^{\mathrm{a}}$ & $\mathrm{D}_{\mathrm{q}}{ }^{\mathrm{a}}$ & $\mathrm{SF}^{\mathrm{b}}$ & SER \\
\hline Hypo & 4.15 & 5.22 & 0.67 & - \\
Norm & 2.07 & 1.99 & 0.48 & 2.0 \\
Hypo SU $1 \mu \mathrm{M}$ & 3.18 & 3.60 & 0.61 & 1.31 \\
Hypo SU $2.5 \mu \mathrm{M}$ & 2.61 & 2.59 & 0.58 & 1.59 \\
\hline
\end{tabular}


sunitinib; SF2, surviving fraction at $2 \mathrm{~Gy} ; \mathrm{D}_{0}$, mean lethal dose; $\mathrm{D}_{\mathrm{q}}$, quasi-threshold dose; SER, surivival enhancement ratio.

respectively. These results indicated a low cytotoxic effect on the growth of ESCC cells. Thus, these low-cytotoxic concentrations $(1$ and $2.5 \mu \mathrm{M})$ were selected for the following assays.

MTT assay was also performed to assess the effect of sunitinib on hypoxic ECA109 cells. ECA109 cells under hypoxic conditions (0.8-1.0\% $\left.\mathrm{pO}_{2}\right)$ exhibited a significant resistance to IR, while sunitinib sensitized hypoxic cancer cells to IR. The cell growth inhibition with sunitinib treatment was significantly lower than that without sunitinib treatment (Fig. 1B).

Sunitinib enhances radiation-induced apoptosis in both normoxic and hypoxic ESCC cells. Annexin-V/PI staining was performed to quantify the apoptosis of hypoxic ESCC cells exposed to IR after sunitinib treatment for $48 \mathrm{~h}$ (Fig. 2A and B). The results revealed that the apoptosis rate was significantly lower in the hypoxic group than in the normoxic group $(\mathrm{P}<0.05)$. Following treatment with sunitinib at 1 or $2.5 \mu \mathrm{M}$, the apoptosis rate was higher compared with that of hypoxia alone $(\mathrm{P}<0.05)$.

Sunitinib radiosensitizes ESCC cells, but does not alter their cell cycle distribution. The percentage of cells in each phase of the cell cycle in the different groups are summarized in Fig. $2 \mathrm{C}$ and D. Compared with the normoxia group, no significant accumulation of ECA109 cells in the G0/G1 or G2/M phases was noted in the hypoxia alone group or in the hypoxia group treated with sunitinib at 1 or $2.5 \mu \mathrm{M}$.

Sunitinib significantly enhances ESCC cell radiosensitivity. Clonogenic survival assays were performed to assess the potential radiosensitization activity of sunitinib. Cells under hypoxic conditions $\left(0.8-1.0 \% \mathrm{pO}_{2}\right)$ exhibited a significant increase in their ability to form colonies following IR, indicating their resistance to IR. However, sunitinib sensitized hypoxic cancer cells to IR significantly. The dose-survival curves are shown in Fig. 3A. The surviving fraction (SF) data were fitted into the following single-hit multi-target model formula: $\mathrm{SF}=1-\left(1-\mathrm{e}^{-\mathrm{D} / \mathrm{D} 0}\right)^{\mathrm{n}}$, where $\mathrm{D}_{0}$ is the mean lethal dose and $\mathrm{D}_{\mathrm{q}}$ is the quasi-threshold dose. The results revealed that the SFs at 2 Gy (SF2)s were 0.48 and 0.67 for ECA109 cells under normoxic and hypoxic conditions, respectively. Upon treatment with sunitinib at 1 or $2.5 \mu \mathrm{M}$, the SF2 of hypoxic cells increased to 0.61 or 0.58 in ECA109 cells, respectively. The survival enhancement ratio (SER) was calculated according to the clonogenic results: $\mathrm{SER}=\mathrm{D}_{0}$ (test group)/ $\mathrm{D}_{0}$ (hypo group). The SERs of hypoxic cells were 1.31 or 1.59 in ECA109 cells treated with sunitinib at 1 or $2.5 \mu \mathrm{M}$, respectively, compared with the hypoxic condition alone (Table I). These data demonstrated that treating hypoxic ESCC cells with sunitinib resulted in a significant radiosensitization effect.

Sunitinib radiosensitizes ESCC cells by inhibiting the expression of HIF-1 $\alpha$ and VEGF. Western blot analysis was performed to confirm the effect of sunitinib on the VEGF and HIF-1 $\alpha$ expression induced by hypoxia. ECA109 cells were treated with 1 or $2.5 \mu \mathrm{M}$ sunitinib for $24 \mathrm{~h}$. It was observed that hypoxia increased the expression of VEGF and HIF-1 $\alpha$. However, sunitinib could inhibit the expression of VEGF and HIF-1 $\alpha$, particularly at high doses (Fig. 3B).

\section{Discussion}

In spite of the excellent progress in IR techniques and treatment strategies, achievements in advanced esophageal 
cancers are still unsatisfactory, with a 5-year survival rate of $20-30 \%$ and a locoregional control rate of only $45 \%(1,17)$. Thus, novel radiosensitizing agents to overcome the resistance to conventional radiotherapeutic interventions are urgently required. The present study demonstrated for the first time that sunitinib could significantly promote the radiosensitivity of ESCC ECA109 cells, and that this promotion was associated with the inhibition HIF-1 $\alpha$ and VEGF expression induced by the hypoxic microenvironment. The present study confirmed that sunitinib could apparently inhibit human ESCC cell viability and proliferation. It was also noticed that sunitinib radiosensitized esophageal cancer cells by inhibiting the clonogenic growth of hypoxic ECA109 cells following IR. Compared with that of the hypoxia and IR groups, the apoptosis rate of the group treated with sunitinib increased in a dose-dependent manner. The radiosensitivity of sunitinib in hypoxic ESCC cells was associated with the inhibition of hypoxia-induced HIF-1 $\alpha$ and VEGF expression. Compared with the normoxia group, there were no changes in cell cycle distribution in the groups subjected to sunitinib. Thus, the radiosensitizing effect of sunitinib may be independent of the cell cycle distribution. These results will expand our understanding of the effect of sunitinib activity, and suggest that sunitinib may be a potential radiosensitizing agent for the treatment of esophageal cancer.

Radiotherapy is a crucial treatment modality for esophageal carcinoma (2). However, due to radioresistance, the radiotherapy effects are often unsuccessful (2). Recent studies have demonstrated that an hypoxic microenvironment is one of the crucial factors in radioresistance to radiation therapy (RT) in solid tumors, resulting from the unbalance between increased oxygen consumption by the extensive growth of tumor cells and decreased oxygen delivery by disordered tumor blood vessels (18). The tumor vasculature was also observed to be an effective target for the cytotoxic effects of RT (19). The inherent resistance of the tumor blood vessels to the cytotoxic effects of RT required to be overcome (19). HIF-1 $\alpha$ is a well-recognized hallmark of hypoxic microenvironments and an important regulator of the hypoxic response, participating in the regulation of aerobic glycolysis to enable the growth of cancer cells $(14,20)$. Previous evidence has suggested that radiation prevented the accumulation of HIF-1 $\alpha$, which protected the tumor vasculature from radiation damage by inducing VEGF expression (6). In addition, tumor cells under hypoxic conditions exhibited cancer cell phenotypes with enhanced pro-survival pathways, acquiring increased malignant potential and resistance to radiotherapy $(21,22)$. Furthermore, preclinical studies consistently demonstrated an increase in radiosensitization upon suppression of HIF-1 $\alpha$ and VEGF $(23,24)$.

In the present study, sunitinib, an oral multi-tyrosine kinase inhibitor, was used, since this agent has demonstrated beneficial effects in clinical phase II studies with patients with advanced esophageal or gastroesophageal junction cancer (25). Sunitinib exhibited broad and potent antitumor activity in breast tumors, pancreatic cancer and colon cancer (11-13). Additionally, sunitinib had been shown to transiently improve tumor oxygenation, normalize tumor vasculature, suppress tumor cycling hypoxia and enhance the tumor response to radiotherapy $(14,26)$. In particular, sunitinib was revealed to inhibit cellular signaling via HIF-1 $\alpha$ and subsequent VEGF in human embryonic stem cell (15), HT-29 colon cancer cells (16) and melanoma xenografts (27). Therefore, the present study first investigated the potential of sunitinib as a potent HIF-1 $\alpha$ inhibitor in ESCC cells, and observed that HIF-1 $\alpha$ and VEGF expression were suppressed by sunitinib. These data suggest that sunitinib could sensitize hypoxic ESCC cells to radiotherapy by inhibiting HIF-1 $\alpha$ and VEGF expression. As the current study was conducted in vitro, future studies should be performed to determine the radiosensitization effect of sunitinib in vivo. Second, the mechanisms by which sunitinib suppressed the expression of HIF-1 $\alpha$ and VEGF were difficult to define, and it is uncertain whether the observed suppression was direct or indirect.

In conclusion, sunitinib increased the radiosensitivity of ESCC cells and led to the suppression of HIF-1 $\alpha$ in the present in vitro study. These results provide support that sunitinib may be a novel radiosensitizer and a promising agent in adjuvant therapy to enhance the effects of radiotherapy for ESCC. However, future studies are required to investigate the molecular mechanisms and confirm these effects prior to its clinical use.

\section{Acknowledgements}

The present study was supported by a project funded by the Priority Academic Program Development of Jiangsu Higher Education Institution (Nanjing, China; grant no. JX10231801), grants from the Key Academic Discipline of Jiangsu Province 'Medical Aspects of Specific Environments' (Nanjing, China), the National Natural Science Foundation of Jiangsu (Nanjing, China; grant no. BK20151174), the Scientific Research of Changzhou (Changzhou, China; grant nos. CJ20159038 and CE20155046) and the Changzhou High Level Medical Talents Training Project (Changzhou, China; grant no. 2016C2LJ026).

\section{References}

1. Torre LA, Bray F, Siegel RL, Ferlay J, Lortet-Tieulent J and Jemal A: Global cancer statistics, 2012. CA Cancer J Clin 65: 87-108, 2015

2. Shridhar R, Almhanna K, Meredith KL, Biagioli MC Chuong MD, Cruz A and Hoffe SE: Radiation therapy and esophageal cancer. Cancer Control 20: 97-110, 2013.

3. Li S, Jiang S, Jiang W, Zhou Y, Shen XY, Luo T, Kong LP and Wang HQ: Anticancer effects of crocetin in human esophageal squamous cell carcinoma KYSE-150 cells. Oncol Lett 9: 1254-1260, 2015

4. Williams KJ, Telfer BA, Xenaki D, Sheridan MR, Desbaillets I, Peters HJ, Honess D, Harris AL, Dachs GU, van der Kogel A and Stratford IJ: Enhanced response to radiotherapy in tumours deficient in the function of hypoxia-inducible factor-1. Radiother Oncol 75: 89-98, 2005.

5. Hsiao HT, Xing L, Deng X, Sun X, Ling CC and Li GC: Hypoxia-targeted triple suicide gene therapy radiosensitizes human colorectal cancer cells. Oncol Rep 32: 723-729, 2014.

6. Semenza GL: Hypoxia-inducible factors: Mediators of cancer progression and targets for cancer therapy. Trends Pharmacol Sci 33: 207-214, 2012 .

7. Harada H, Inoue M, Itasaka S, Hirota K, Morinibu A, Shinomiya K, Zeng L, Ou G, Zhu Y, Yoshimura M, et al: Cancer cells that survive radiation therapy acquire HIF-1 activity and translocate towards tumour blood vessels. Nat Commun 3: 783, 2012. 
8. Sohda M, Ishikawa H, Masuda N, Kato H, Miyazaki T, Nakajima M, Fukuchi M, Manda R, Fukai Y, Sakurai H and Kuwano H: Pretreatment evaluation of combined HIF-1alpha, p53 and p21 expression is a useful and sensitive indicator of response to radiation and chemotherapy in esophageal cancer. Int J Cancer 110: 838-844, 2004.

9. Moon SY, Chang HW, Roh JL, Kim GC, Choi SH, Lee SW, Cho KJ, Nam SY and Kim SY: Using YC-1 to overcome the radioresistance of hypoxic cancer cells. Oral Oncol 45: 915-919, 2009.

10. Staab A, Fleischer M, Loeffler J, Said HM, Katzer A, Plathow C, Einsele H, Flentje M and Vordermark D: Small interfering RNA targeting HIF-1 $\alpha$ reduces hypoxia-dependent transcription and radiosensitizes hypoxic HT 1080 human fibrosarcoma cells in vitro. Strahlenther Onkol 187: 252-259, 2011.

11. El Kaffas A, Al-Mahrouki A, Tran WT, Giles A and Czarnota GJ: Sunitinib effects on the radiation response of endothelial and breast tumor cells. Microvasc Res 92: 1-9, 2014.

12. Cuneo KC, Geng L, Fu A, Orton D, Hallahan DE and Chakravarthy AB: SU11248 (sunitinib) sensitizes pancreatic cancer to the cytotoxic effects of ionizing radiation. Int $J$ Radiat Oncol Biol Phys 71: 873-879, 2008.

13. Sun J, Sun Q, Brown MF, Dudgeon C, Chandler J, Xu X, Shu Y, Zhang L and Yu J: The multi-targeted kinase inhibitor sunitinib induces apoptosis in colon cancer cells via PUMA. PloS One 7: e43158, 2012.

14. Matsumoto S, Batra S, Saito K, Yasui H, Choudhuri R, Gadisetti C, Subramanian S, Devasahayam N, Munasinghe JP, Mitchell JB and Krishna MC: Antiangiogenic agent sunitinib transiently increases tumor oxygenation and suppresses cycling hypoxia. Cancer Res 71: 6350-6359, 2011.

15. Chen G, Xu X, Zhang L, Fu Y, Wang M, Gu H and Xie X: Blocking autocrine VEGF signaling by sunitinib, an anti-cancer drug, promotes embryonic stem cell self-renewal and somatic cell reprogramming. Cell Res 24: 1121-1136, 2014.

16. Shin HW, Cho CH, Kim TY and Park JW: Sunitinib deregulates tumor adaptation to hypoxia by inhibiting HIF-1alpha synthesis in HT-29 colon cancer cells. Biochem Biophys Res Commun 398: 205-211, 2010.

17. Minsky BD, Pajak TF, Ginsberg RJ, Pisansky TM, Martenson J, Komaki R, Okawara G, Rosenthal SA and Kelsen DP: INT 0123 (Radiation Therapy Oncology Group 94-05) phase III trial of combined-modality therapy for esophageal cancer: High-dose versus standard-dose radiation therapy. J Clin Oncol 20: 1167-1174, 2002 .
18. Yoshimura $M$, Itasaka $S$, Harada $H$ and Hiraoka $M$ : Microenvironment and radiation therapy. Biomed Res Int 2013: 685308, 2013.

19. Kim DW, Huamani J, Fu A and Hallahan DE: Molecular strategies targeting the host component of cancer to enhance tumor response to radiation therapy. Int J Radiat Oncol Biol Phys 64: 38-46, 2006.

20. Sadri N and Zhang PJ: Hypoxia-inducible factors: Mediators of cancer progression; prognostic and therapeutic targets in soft tissue sarcomas. Cancers (Basel) 5: 320-333, 2013.

21. Martinive P, Defresne F, Bouzin C, Saliez J, Lair F, Grégoire V, Michiels C, Dessy C and Feron O: Preconditioning of the tumor vasculature and tumor cells by intermittent hypoxia: Implications for anticancer therapies. Cancer Res 66: 11736-11744, 2006

22. Dewhirst MW, Cao Y and Moeller B: Cycling hypoxia and free radicals regulate angiogenesis and radiotherapy response. Nat Rev Cancer 8: 425-437, 2008

23. Zhang C, Yang X, Zhang Q, Yang B, Xu L, Qin Q, Zhu H, Liu J, Cai J, Tao G, et al: Berberine radiosensitizes human nasopharyngeal carcinoma by suppressing hypoxia-inducible factor-1alpha expression. Acta Otolaryngol 134: 185-192, 2014

24. Meijer TW, Kaanders JH, Span PN and Bussink J: Targeting hypoxia, HIF-1, and tumor glucose metabolism to improve radiotherapy efficacy. Clin Cancer Res 18: 5585-5594, 2012.

25. Schmitt JM, Sommers SR, Fisher W, Ansari R, Robin E, Koneru K, McClean J, Liu Z, Tong Y and Hanna N: Sunitinib plus paclitaxel in patients with advanced esophageal cancer: A phase II study from the Hoosier Oncology Group. J Thorac Oncol 7: 760-763, 2012.

26. Chen FH, Chiang CS, Wang CC, Fu SY, Tsai CS, Jung SM, Wen CJ, Lee CC and Hong JH: Vasculatures in tumors growing from preirradiated tissues: Formed by vasculogenesis and resistant to radiation and antiangiogenic therapy. Int $\mathbf{J}$ Radiat Oncol Biol Phys 80: 1512-1521, 2011.

27. Gaustad JV, Pozdniakova V, Hompland T, Simonsen TG and Rofstad EK: Magnetic resonance imaging identifies early effects of sunitinib treatment in human melanoma xenografts. J Exp Clin Cancer Res 32: 93, 2013. 